\title{
Quality of Life and Mild Cognitive Impairment in Early Parkinson's Disease: Does Subtype Matter?
}

\author{
Rachael A. Lawson ${ }^{\mathrm{a}, *}$, Alison J. Yarnalla ${ }^{\mathrm{a}}$, Gordon W. Duncan ${ }^{\mathrm{a}}$, Tien K. Khoo ${ }^{\mathrm{b}}$, David P. Breen ${ }^{\mathrm{c}}$, \\ Roger A. Barker ${ }^{\mathrm{c}}$, Daniel Collerton ${ }^{\mathrm{a}}$, John-Paul Taylor ${ }^{\mathrm{a}}$ and David J. Burn ${ }^{\mathrm{a}}$ \\ ${ }^{\mathrm{a}}$ Institute for Ageing and Health, Newcastle University, Newcastle upon Tyne, UK \\ ${ }^{\mathrm{b}}$ Griffith Health Institute \& School of Medicine, Griffith University, Gold Coast, Australia \\ ${ }^{\mathrm{c}}$ John van Geest Centre for Brain Repair, University of Cambridge, Cambridge, UK
}

\begin{abstract}
We evaluated the association between mild cognitive impairment (MCI) subtypes and quality of life (QoL) in 219 newly diagnosed Parkinson's disease (PD) patients without dementia. Participants completed neuropsychological tests of attention, executive function, visuospatial function, memory, and language, and reported QoL using the Parkinson's Disease Questionnaire. Impairments were most common in executive function, memory and attention. MCI subtypes were classified according to Movement Disorder Society Task Force criteria. More severe cognitive impairment was associated with poorer quality of life $(p=0.01)$, but subtype of impairment was not $(p>0.10)$, suggesting that the nature of cognitive impairment is less significant than its severity.
\end{abstract}

Keywords: Parkinson's disease, quality of life, mild cognitive impairment, subtypes

\section{INTRODUCTION}

For the individual living with Parkinson's disease (PD), the development of dementia (PDD) has a significant impact upon quality of life (QoL) [1]. Mild cognitive impairment in PD (PD-MCI) may be a precursor to PDD, and thus may also impact on QoL [2]. Furthermore, QoL may be affected by particular subtypes of MCI [1], where impairments in multiple domains may have greater cognitive burden and thus may cause greater difficulties in activities of daily

\footnotetext{
*Correspondence to: Rachael A. Lawson, Clinical Ageing Research Unit, Institute for Ageing and Health, Newcastle University, Campus for Ageing and Vitality, Newcastle upon Tyne, NE4 5PL, UK. Tel.: +44 191208 1277; Fax: +44 191208 1251; E-mail: rachael.lawson@ncl.ac.uk.
}

living (ADL) and poorer QoL [3, 4]. Additionally, specific domains, e.g. deficits in attention and executive function which are common in PD, may be more detrimental to ADL and QoL [4-6].

To the authors' knowledge, there are currently no studies investigating whether QoL in people with PDMCI differs between subtypes. Such information could help guide clinicians as to what pharmacological and non-pharmacological interventions might be particularly effective [7]; e.g. cholinesterase inhibitors for attention could improve QoL [5, 8].

We evaluated the impact of PD-MCI subtypes upon QoL in a large cohort of patients with newly diagnosed PD. We hypothesised that PD-MCI would negatively affect QoL and that the effect across the different MCI subtypes would not be equal, with executive dysfunction and attention having a greater impact. 


\section{PARTICIPANTS AND METHODS}

Newly diagnosed idiopathic PD patients, as per Queen's Square Brain Bank criteria [9], were recruited from community and outpatient clinics. Participants and age-sex matched healthy controls completed a schedule of neuropsychological assessments covering five cognitive domains: attention, executive function, visuospatial function, language and memory [10]. Attention was assessed using Power of Attention and Digit vigilance from the Cognitive Drug Research Battery [11]. Executive function was assessed using the One touch Tower of London from the Cambridge Neuropsychological Test Automated Battery (CANTAB) [12], phonemic fluency (number of words generated in 60 seconds beginning with the letter F) and semantic fluency (number of names of animals generated in 90 seconds) [13, 14]. Memory was assessed using Spatial and Pattern Recognition Memory, and Paired Associate Learning subsets from the CANTAB. Visuospatial dysfunction was measured using a modified scoring for copying interlocking pentagons [15]. Language dysfunction was measured using the naming and language scores from the Montreal Cognitive Assessment (MoCA) [16]. Premorbid intelligence was measured using the National Adult Reading Test (NART) [17].

As our study design predated the Movement Disorder Society (MDS) Task Force PD-MCI criteria, we used a modified Level II criteria, which is described in full elsewhere [10], at cut offs of 1.0, 1.5 or 2.0 standard deviations (SD) below normative values (controls) to classify PD-MCI. For non-normally distributed neuropsychological scores, an approximation to the normal distribution was used to calculate cut-offs. Single-domain PD-MCI was defined as impairment in two tests in the same domain; multi-domain classification required at least one impaired test in more than one domain [18]. Participants were then classified according to impairments in specific domains.

The Parkinson's Disease Questionnaire (PDQ-39) single index score was used to assess QoL [19], where a score of 0 indicates best QoL and a maximum score of 100 indicates worst QoL. This questionnaire is widely used and recommended for measuring QoL in PD [20].

This study was approved by the Newcastle and North Tyneside Research Ethics Committee. All participants provided written informed consent.

Statistical analyses were performed using SPSS Version 19.0. Comparisons of means between two groups or more than two groups were performed using independent $t$-tests, Mann-Whitney U test or KruskalWallis tests as appropriate..

\section{RESULTS}

There were no significant differences between PD participants $(n=219)$ and controls $(n=99)$ in terms of age (mean of $65.9 \pm 9.7$ vs $67.9 \pm 8.2$ years; $p=0.06$ ), sex (males $63.9 \%$ vs $55 \% ; p=0.11$ ), level of education (mean of $13.1 \pm 3.4$ vs $12.8 \pm 3.6$ years; $p=0.36$ ) and NART scores (mean of $115.8 \pm 8.7$ vs $114.3 \pm 10.3$; $p=0.37$ ). Mean duration of PD was $5.5 \pm 5.0$ months, $83 \%$ were rated as Hoehn and Yahr stage 1 or 2 .

Using our modified MDS criteria 66\% $(n=144)$ were classified as having PD-MCI $(\geq 1$ SD below normative data); they were significantly older $(p<0.01)$, had completed fewer years of education $(p<0.01)$ and more severe motor symptoms $(p<0.01)$. QoL scores were significantly worse for participants with PD-MCI (mean of $24.3 \pm 19.4$ vs 31.2 $\pm 23.3 ; p=0.03$ ).

Participants were grouped by MCI severity, participants scoring: $\geq 1$ SD but $<1.5$ SD below normative data (PD-MCI 1SD, $n=51$ ); $\geq 1.5$ SD but $<2$ SD below normative data (PD-MCI 1.5 SD, $n=44$ ); and $\geq 2$ SD below normative data (PD-MCI 2 SD, $n=49$ ). Post hoc analysis showed PDQ-39 scores were significantly worse using the 2 SD PD-MCI cut off (mean of $38.2 \pm 25.2 ; p=0.01)$ compared to $1 \mathrm{SD}$ and $1.5 \mathrm{SD}$ cut off (mean of $26.6 \pm 21.9$ and $28.8 \pm 21.2$ respectively), suggesting that more severe MCI was a major contributor to poor quality of life in the MCI group.

\section{Subtypes of mild cognitive impairment}

The MDS PD-MCI criteria identified 22 subtypes (Fig. 1). Significantly more subjects were classified as having multi-domain than single-domain MCI $(p<0.01)$. Executive function $(67 \%)$, memory $(61 \%)$ and attention $(51 \%)$ were most frequently impaired. The most common subtypes were memory+executive function $(22 \%)$, attention+executive function $(13 \%)$ and attention+memory+executive function $(13 \%)$. Figure 1 also shows that the number of participants in each subtype was relatively small; the first seven subtypes accounted for the majority of participants, with those after the divide making up less than $5 \%$ of participants in each subgroup.

Figure 2 shows a radar plot of the seven most frequent subtypes and PDQ-39 score by PD-MCI cut off; values extending from the centre of plot indicate worse QoL. In most subtypes, QoL decreased as cognitive impairment increased. Single-domain attention and multi-domain attention+memory+executive function tended to be associated with poorer QoL at the 2 SD cognitive cut off compared to other cut offs, but 


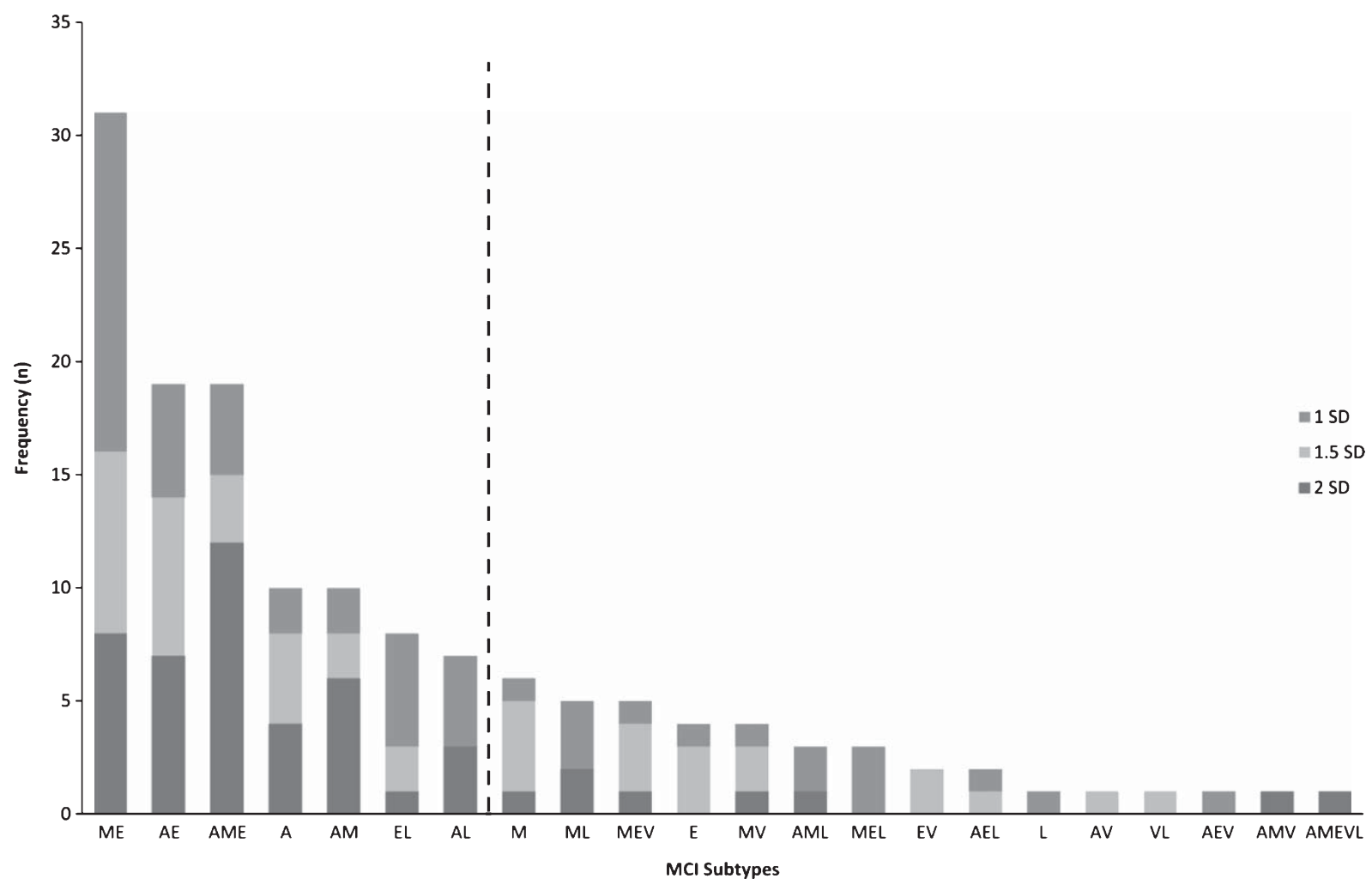

Fig. 1. Subtypes of mild cognitive impairment in participants with newly diagnosed Parkinson's disease. Subtypes of mild cognitive impairment (MCI): $\mathrm{A}=$ Attention; $\mathrm{E}=$ Executive function; $\mathrm{L}=$ Language; $\mathrm{M}=$ Memory; $\mathrm{V}=$ Visuospatial function.

overall there were no significant differences in QoL between MCI subtypes $(p>0.10)$.

We conducted a secondary analysis using classifications outlined by Marras, et al. [21], which required two tests impaired in at least one domain. This identified fewer PD-MCI participants ( $\geq 1$ SD below normative data; $n=104$ ) with significantly more single-domain impairments (76\%). The most common subtypes were single-domain executive function (25\%) and memory (19\%); memory+executive function remained the most common multiple-domain subtype $(5 \%)$. There were no significant differences in QoL between subtypes $(p>0.10)$.

\section{DISCUSSION}

In this large incidence cohort, we found that QoL decreased as severity of MCI increased. We identified a number of PD-MCI subtypes and found more multidomain impairments than single-domain, although there were no significant differences in QoL between subtypes. This may suggest that in PD-MCI it is the severity of cognitive impairment, rather than the nature of impairment, that impacts on QoL.

Impairment was most common in executive function, memory and attention. Two thirds of PD-MCI participants had executive dysfunction. A recent study has also observed high frequencies of executive dysfunction in PD-MCI [22], which can impair ADL [8]. Memory was the second most common impaired domain, which was also reported by Goldman, et al. [22], and has been shown to negatively impact on QoL $[23,24]$. Half of PD-MCI participants had attentional dysfunction, which was also the most common single-domain subtype. This has also been observed in a previous study [25] and has been shown to significantly impact physical functioning and social interaction [5]. Significantly, only $15 \%$ of PD-MCI subjects had single-domain impairment. The high proportion of multi-domain impairments has also been found in other studies [21, 22, 26, 27].

To our knowledge, this is the first study to explore the relationship between QoL and PD-MCI subtypes. More severe impairment in single-domain attention and multi-domain attention+memory+executive 


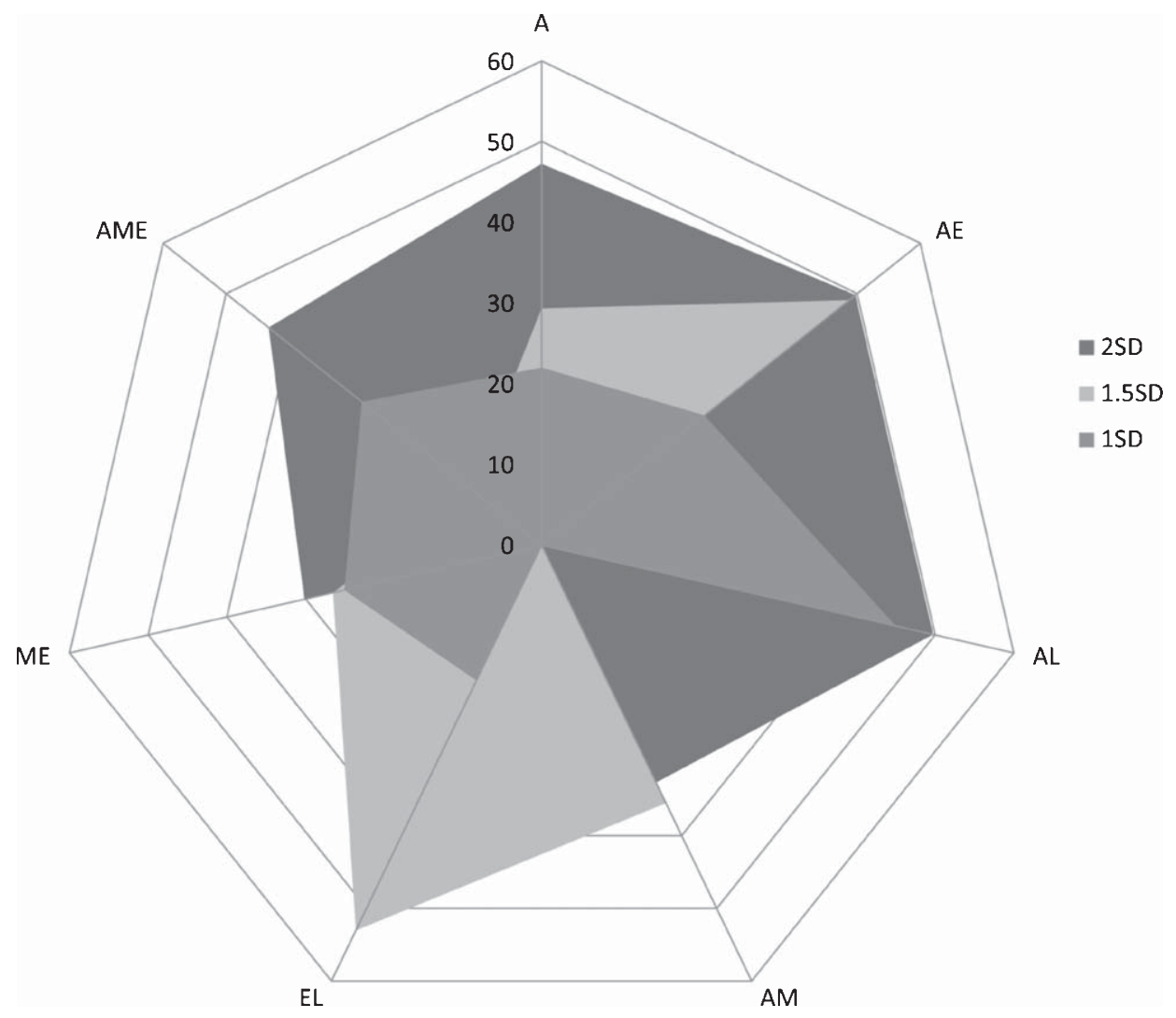

Fig. 2. Subtypes of mild cognitive impairment and PDQ-39 scores. Radar plot of mean PDQ-39 scores of each cut-off, (1 SD, 1.5 SD and 2 SD below normative values) for the most frequent subtypes of mild cognitive impairment. Scale on graph is PDQ-39 score, where higher values indicate worse quality of life. $\mathrm{A}=$ Attention; $\mathrm{E}=$ Executive function; $\mathrm{L}=$ Language; $\mathrm{M}=$ Memory; $\mathrm{V}=$ Visuospatial function; $\mathrm{PDQ}-$ $39=$ Parkinson's Disease Questionnaire.

function subtypes tended to be associated with poorer QoL, although we did not find any significant differences in QoL score between subtypes. Previous studies have variable findings between cognitive domains. Attention and memory problems have been associated with worse QoL [23], whilst another study found visuospatial function, executive function and attention in PD participants affected QoL [4]. Impairment in specific domains can inhibit everyday functioning and ADL [5], or results in less effective coping strategies [6]. Therefore, there may be an interaction between PD-MCI and other lifestyle variables; those with higher premorbid functioning may find the challenge of having MCI greater [24].

The strength of this study is in the large cohort of newly diagnosed PD participants with an age-matched control group. Limitations include its design that preceded the publication of the MDS PD-MCI criteria. We therefore used a modified version with an unequal numbers of tests per domain comprising only one test for visuospatial function and more than two tests for memory and executive function. This has implications for subtyping and may increase the frequency of impairments in these domains. The small number of participants in each subtype reduced statistical power, decreasing the sensitivity of our study to detect subtle differences between subtypes.

In summary, PD-MCI is complex with severity of impairment, rather than subtype, affecting QoL. It could be inferred that the current MDS guidelines for subtyping PD-MCI may not be optimal, we identified 22 subtypes using the proposed guidelines. Numerous subtypes may be impractical in clinical settings; this could indicate that subtyping is of no real significance to patients and that their QoL is not affected by the specific nature of the impairment.

\section{ACKNOWLEDGMENTS}

The ICICLE-PD study group would like to thank all participants for their contribution towards the study. ICICLE-PD was funded by Parkinson's UK. This work 
was also supported by the UK NIHR Biomedical Research Centre for Ageing and Age-Related Disease, UK NIHR Biomedical Research Unit in Lewy Body Dementia awards to the Newcastle upon Tyne Hospitals NHS Foundation Trust and the UK NIHR Biomedical Research Centre award to the University of Cambridge/Addenbrooke's Hospital. DPB has been recipient of a Raymond and Beverly Sackler Studentship. The views expressed are those of the authors and not necessarily those of the NHS, the NIHR or the Department of Health. JPT is funded by the Wellcome Trust Intermediate Clinical Fellowship.

\section{CONFLICTS OF INTEREST}

The authors have no conflict of interest to report.

\section{REFERENCES}

[1] Leroi I, McDonald K, Pantula H, \& Harbishettar V (2012) Cognitive Impairment in Parkinson Disease: Impact on Quality of Life, Disability, and Caregiver Burden. J Geriatr Psychiatry Neurol, 25, 208-214.

[2] Reginold W, Duff-Canning S, Meaney C, Armstrong MJ, Fox S, Rothberg B, Zadikoff C, Kennedy N, Gill D, Eslinger P, Marshall F, Mapstone M, Chou KL, Persad C, Litvan I, Mast B, Tang-Wai D, Lang AE, \& Marras C (2013) Impact of Mild Cognitive Impairment on Health-Related Quality of Life in Parkinson's Disease. Dement Geriatr Cogn Disord, 36, 67-75.

[3] Goldman JG, Weis H, Stebbins G, Bernard B, \& Goetz CG (2012) Clinical differences among mild cognitive impairment subtypes in Parkinson's disease. Mov Disord, 27, 1129-1136.

[4] Klepac N, Trkulja V, Relja M, \& Babic T (2008) Is quality of life in non-demented Parkinson's disease patients related to cognitive performance? A clinic-based cross-sectional study. Eur J Neurol, 15, 128-133.

[5] Bronnick K, Ehrt U, Emre M, De Deyn PP, Wesnes K, Tekin S, \& Aarsland D (2006) Attentional deficits affect activities of daily living in dementia-associated with Parkinson's disease. Journal of Neurology, Neurosurgery \& Psychiatry, 77, 11361142.

[6] Kudlicka A, Clare L, \& Hindle JV (2014) Quality of life, health status and caregiver burden in Parkinson's disease: Relationship to executive functioning. Int J Geriatr Psychiatry, 29, 68-76.

[7] Hindle JV, Petrelli A, Clare L, \& Kalbe E (2013) Nonpharmacological enhancement of cognitive function in Parkinson's disease: A systematic review. Mov Disord, 28, 1034-1049.

[8] Kehagia AA, Barker RA, \& Robbins TW (2010) Neuropsychological and clinical heterogeneity of cognitive impairment and dementia in patients with Parkinson's disease. Lancet Neurol, 9, 1200-1213.

[9] Hughes AJ, Daniel SE, Kilford L, \& Lees AJ (1992) Accuracy of clinical diagnosis of idiopathic Parkinson's disease: A clinico-pathological study of 100 cases. J Neurol Neurosurg Psychiatry, 55, 181-184.

[10] Yarnall AJ, Breen DP, Duncan GW, Khoo TK, Coleman SY, Firbank MJ, Nombela C, Winder-Rhodes S, Evans JR, Rowe JB, Mollenhauer B, Kruse N, Hudson G, Chinnery PF, O’Brien JT, Robbins TW, Wesnes K, Brooks DJ, Barker
RA, \& Burn DJ (2013) Characterizing mild cognitive impairment in incident Parkinson disease: The ICICLE-PD Study. Neurology.

[11] Nicholl CG, Lynch S, Kelly CA, White L, Simpson PM, Wesnes KA, \& Pitt BMN (1995) The cognitive drug research computerized assessment system in the evaluation of early dementia-is speed of the essence? Int J Geriatr Psychiatry, 10, 199-206.

[12] Robbins TW, James M, Owen AM, Sahakian BJ, McInnes L, \& Rabbitt P (1994) Cambridge Neuropsychological Test Automated Battery (CANTAB): A factor analytic study of a large sample of normal elderly volunteers. Dementia, $\mathbf{5}$, 266-281.

[13] Benton A (1968) Differential behavioral effects in frontal lobe disease. Neuropsychologia, 6, 53-60.

[14] Tombaugh TN, Kozak J, \& Rees L (1999) Normative data stratified by age and education for two measures of verbal fluency: FAS and animal naming. Arch Clin Neuropsychol 14, 167-177.

[15] Ala TA, Hughes LF, Kyrouac GA, Ghobrial MW, \& Elble RJ (2001) Pentagon copying is more impaired in dementia with Lewy bodies than in Alzheimer's disease. J Neurol Neurosurg Psychiatry, 70, 483-488.

[16] Nasreddine ZS, Phillips NA, Bédirian V, Charbonneau S, Whitehead V, Collin I, Cummings JL, \& Chertkow H (2005) The Montreal Cognitive Assessment, MoCA: A Brief Screening Tool For Mild Cognitive Impairment. J Am Geriatr Soc, 53, 695-699.

[17] Mathias JL, Bowden SC, \& Barrett-Woodbridge M (2007) Accuracy of the Wechsler Test of Adult Reading (WTAR) and National Adult Reading Test (NART) when estimating IQ in a healthy Australian sample. Aust Psychol, 42, 49-56.

[18] Litvan I, Goldman JG, Tröster AI, Schmand BA, Weintraub D, Petersen RC, Mollenhauer B, Adler CH, Marder K, WilliamsGray CH, Aarsland D, Kulisevsky J, Rodriguez-Oroz MC, Burn DJ, Barker RA, \& Emre M (2012) Diagnostic criteria for mild cognitive impairment in Parkinson's disease: Movement Disorder Society Task Force guidelines. Mov Disord, 27, 349356.

[19] Jenkinson C, Fitzpatrick RAY, Peto VIV, Greenhall R, \& Hyman N (1997) The Parkinson's Disease Questionnaire (PDQ-39): Development and validation of a Parkinson's disease summary index score. Age Ageing, 26, 353-357.

[20] Martinez-Martin P, Jeukens-Visser M, Lyons KE, RodriguezBlazquez C, Selai C, Siderowf A, Welsh M, Poewe W, Rascol O, Sampaio C, Stebbins GT, Goetz CG, \& Schrag A (2011) Health-related quality-of-life scales in Parkinson's disease: Critique and recommendations. Movement Disorders, 26, 2371-2380.

[21] Marras C, Armstrong MJ, Meaney CA, Fox S, Rothberg B, Reginold W, Tang-Wai DF, Gill D, Eslinger PJ, Zadikoff C, Kennedy N, Marshall FJ, Mapstone M, Chou KL, Persad C, Litvan I, Mast BT, Gerstenecker AT, Weintraub S, \& Duff-Canning S (2013) Measuring mild cognitive impairment in patients with Parkinson's disease. Mov Disord, 24, 1641-1649.

[22] Goldman JG, Holden S, Bernard B, Ouyang B, Goetz CG, \& Stebbins GT (2013) Defining optimal cutoff scores for cognitive impairment using Movement Disorder Society Task Force criteria for mild cognitive impairment in Parkinson's disease. Mov Disord, 28, 1972-1979.

[23] Barone P, Antonini A, Colosimo C, Marconi R, Morgante L, Avarello TP, Bottacchi E, Cannas A, Ceravolo G, Ceravolo R, Cicarelli G, Gaglio RM, Giglia RM, Iemolo F, Manfredi M, Meco G, Nicoletti A, Pederzoli M, Petrone A, Pisani A, 
Pontieri FE, Quatrale R, Ramat S, Scala R, Volpe G, Zappulla S, Bentivoglio AR, Stocchi F, Trianni G, \& Dotto PD (2009) The PRIAMO study: A multicenter assessment of nonmotor symptoms and their impact on quality of life in Parkinson's disease. Mov Disord, 24, 1641-1649.

[24] Trigg R, Watts S, Jones R, \& Tod A (2011) Predictors of quality of life ratings from persons with dementia: The role of insight. Int J Geriatr Psychiatry, 26, 83-91.

[25] Dalrymple-Alford JC, Livingston L, MacAskill MR, Graham C, Melzer TR, Porter RJ, Watts R, \& Anderson TJ (2011)
Characterizing mild cognitive impairment in Parkinson's disease. Mov Disord, 26, 629-636.

[26] Aarsland D, Brønnick K, Larsen JP, Tysnes OB, Alves G, \& For the Norwegian Park West Study G (2009) Cognitive impairment in incident, untreated Parkinson disease: The Norwegian ParkWest Study. Neurology, 72, 1121-1126.

[27] Janvin CC, Larsen JP, Aarsland D, \& Hugdahl K (2006) Subtypes of mild cognitive impairment in Parkinson's disease: Progression to dementia. Mov Disord, 21, 1343-1349. 